Ab Kadir, M. A. B. (in press) Critical thinking and learner diversity in the Australian Curriculum: implications and epistemological tensions? In: International Journal of the Pedagogies of Learning.

\title{
Critical thinking and learner diversity in the Australian Curriculum: implications and epistemological tensions?
}

\begin{abstract}
The new Australian Curriculum aims to prepare school leavers for the $21^{\text {st }}$ century and in doing so, its curriculum documents mandate the development of critical and creative thinking in school leavers as one of its priorities. Identified as one of the general capabilities in the curriculum, critical and creative thinking is also seen as a key dimension in preparing 'students to live and work in the $21^{\text {st }}$ century' as well as being 'fundamental to effective learning'. More broadly, the $\mathrm{AC}$ is also envisioned to be a curriculum that is inclusive and one that embraces learner diversity, especially in the context of increasing student diversity in Australian classrooms. However, an examination of the understandings of critical thinking in the AC suggest that they are underpinned by Western traditions and epistemologies. Such Western notions of critical thinking are the norm and prevalent in numerous global educational reforms. However, what might require further examination is how such Western understandings of critical thinking and their undergirding epistemologies might engender tensions in the Australian context of learners of increasing diverse epistemologies and cultures which includes the non-Western. It is in light of this that this paper examines the implications and tensions that could be engendered between the distinct Western epistemologies underpinning the understandings of and approaches to critical thinking, on the one hand, and learners' of non-Western epistemologies and cultures, on the other.
\end{abstract}

\section{Introduction}

In this paper, I focus on one aspect of the Australian Curriculum (AC), notably one of its seven key 'general capabilities' - that is, critical and creative thinking (ACARA, 2015). In particular, this focus entails the examination of the manner in which critical thinking is conceptualised in the AC in the context of literature and research in the area. I also examine the Western precepts and epistemologies that underpin these understandings of critical thinking and set this against the Australian context of increasing learner diversity in which learners have been shaped by diverse cultures and epistemologies that include the non-Western. I suggest that in light of these contrasting epistemological contexts, that of the Western epistemologies that shape critical thinking understandings and approaches and that of the non-Western learner cultures and epistemologies that are becoming more prevalent in the Australian classrooms, epistemological tensions could be engendered. I highlight some of the pedagogical implications and epistemological tensions for learners, and teachers in the Australian Curriculum who are tasked with developing critical thinkers in the context of increasing student diversity. Finally, I propose some recommendations to mitigate these tensions. But first I begin this paper by framing the role of critical thinking in education in the $21^{\text {st }}$ century before proceeding to the subsequent sections.

\section{Education in the 21st century and critical thinking}

Many educators agree that the ability to think critically is a key skill for survival in an everchanging world and the foundation of the contemporary education system (Berliner, 2009; 
Ab Kadir, M. A. B. (in press) Critical thinking and learner diversity in the Australian Curriculum: implications and epistemological tensions? In: International Journal of the Pedagogies of Learning.

Lipman, 2003; Paul, 1995; Scheffler, 1989). Developing the ability to think critically is indeed an imperative in a rapidly changing world which demands more of individuals in their personal, social and professional domains. The unprecedented impact of globalization requires the intellectual ability to manage competently one's personal and social spaces which are continually being redefined by the forces of globalization. Hunt (1995) poses the question, 'Will we be smart enough?' in his examination of the skills which will be needed by the workforce of tomorrow and he argues that individuals' quality of life and even the future state of the planet are dependent on how this question is addressed. This claim seems to be supported by a study on 360 adults which found that those who attained higher scores in an assessment of critical thinking described fewer negative life consequences linked with poor decision making such as leaving a new job after a week and having their utilities supply terminated due to overdue bills (deBruin, Parker, \& Fischhoff, 2007).

Thus, the paradigm shift in the focus of education to the development of critical thinking can be attributed to the need to ensure that the citizens of tomorrow are well-equipped to survive in an increasingly complex world. It is undeniable that today's education systems shoulder the responsibility of producing the work force of an increasingly competitive knowledge based economy in which the ability to think critically is essential. And in today's era, the explicit recognition of critical thinking as a vital part of education is illustrated by the recalibration of educational goals by policy makers and education stakeholders in which the incorporation of thinking is an essential part of the educational reform agenda. For instance, educational systems in North America, the UK (Bailin, Case, Coombs et. al, 1999) and in Asia Pacific countries, such as Singapore (Goh, 1997) and Malaysia (Nagappan, 1998) have embarked on such reforms in which critical thinking is identified as a key educational outcome. And Australia is no different with its new Australian Curriculum that prioritizes critical (and creative thinking) (ACARA, 2015).

\section{Critical (and creative thinking) in the Australian Curriculum: what, why, how and for whom?}

The impetus behind the inclusion of critical and creative thinking in the Australian Curriculum is found in The Melbourne Declaration on Educational Goals for Young Australians (MCEETYA). It 'recognises that critical and creative thinking are fundamental to students becoming successful learners. Thinking that is productive, purposeful and intentional is at the centre of effective learning' (MCEETYA, 2008). The Australian Curriculum clearly underscores the importance of such thinking in its act of making it one of the seven key 'general capabilities' to be developed in all learners in its adherence to student diversity (ACARA, 2013). Highlighting explicitly the importance of critical and creative thinking, it states

Responding to the challenges of the twenty-first century - with its complex environmental, social and economic pressures - requires young people to be creative, innovative, enterprising and adaptable, with the motivation, confidence and skills to use critical and creative thinking purposefully (ACARA, 2015).

According to the Australian Curriculum, critical and creative thinking are not seen as interchangeable but they are inextricably linked, 'bringing complementary dimensions to thinking and learning' (ACARA, 2015). This understanding seems to adopt an integrated 
Ab Kadir, M. A. B. (in press) Critical thinking and learner diversity in the Australian Curriculum: implications and epistemological tensions? In: International Journal of the Pedagogies of Learning.

perspective which is consistent with what some educationists propose. For instance, taking the notion of creative thinking in the broad sense, Paul (1995) sees creativity in thinking as 'making, as a process of creating thought - a process that brings thoughts into being to organise, shape, interpret, and makes sense of the world' (Paul, 1995, p. 198; emphasis in original). This is echoed by the curriculum's articulated ideas of creative thinking which includes 'to form something original, sifting and refining ideas to discover possibilities, constructing theories and objects' (ACARA, 2015), skills which certainly will be vital in prospering in a knowledge based economy and addressing multifaceted global issues.

On the other hand, criticality is considered the process of 'judging' and 'assessing' and this is reflected in the curriculum in which critical thinking is seen as the ability 'to recognise or develop an argument, use evidence in support of that argument, draw reasoned conclusions, and use information to solve problems' (ACARA, 2015). Thus, it could be said that in the integrated perspective adopted, the act of thinking well, or excellence in thought, requires practically all of the time for the mind to both produce and assess synchronously. In this regard, critical thinking is a necessary component of creative thinking and is 'inseparable' from it. In other words, 'creativity presupposes criticality and criticality creativity' (Paul, 1995, p.198).

This conflation and interlinking between the two seem to be inherent in the Australian Curriculum documents' suggestion that 'critical and creative thinking learning continuum is organised into four interrelated elements' and these are 'inquiring - identifying, exploring and organising information and ideas; generating ideas, possibilities and actions; reflecting on thinking and processes; and analysing, synthesising and evaluating reasoning and procedures' (ACARA, 2015). Moreover, the curriculum's reference of critical and creative thinking in the singular further supports the contention that both of these are closely interlinked and are indeed 'inseparable'. Hence, in this sense, the focus on critical thinking in the curriculum (as with in this paper), ipso facto, also encompasses creative thinking.

\section{Unpacking understandings of critical thinking in the Australian Curriculum}

The literature on critical thinking is replete with the different ways of conceptualizing it with no consensus of what it should entail. Some theorists such as Sigel (1984), Bloom (1956) and Gardner (2008) see it as a set of cognitive skills and capacities respectively. For instance, Sigel (1984) views it as 'an active process involving a number of denotable mental operations such as induction, deduction, reasoning, sequencing, classification and definition of relationships' (p.18). Gardner's five minds - disciplined, synthesizing, creative, respectful and ethical - suggest the types of thinking capacities that will be key in the future. Bloom's taxonomy of six cognitive categories - knowledge, comprehension, application, analysis, synthesis and evaluation comprises lower-order to higher-order thinking skills in which the higher-order skills such as analysis, synthesis and evaluation are associated with critical thinking (Anderson et al. 2001; Krathwohl, 2002; Paul, 1995). Collectively, these views seem to be echoed in the Australian Curriculum when it articulates that critical thinking includes the ability 'to recognise or develop an argument, use evidence in support of that argument, draw reasoned conclusions, and use information to solve problems' (ACARA, 2015).

Other theorists like Ritchhart (2001, 2002), Tishman, Jay and Perkins (1995) emphasize thinking dispositions in which the notion of 'intellectual character' (Ritchhart, 2002), for example, 
Ab Kadir, M. A. B. (in press) Critical thinking and learner diversity in the Australian Curriculum: implications and epistemological tensions? In: International Journal of the Pedagogies of Learning.

captures this dispositional dimension. 'Dispositions' is seen as the 'characteristics that animate, motivate, and direct our abilities toward good and productive thinking and are recognised in the patterns of our frequently exhibited, voluntary behaviour' (Ritchhart, 2002, p. 21). For instance, Ritchhart's idea of 'intellectual character' consists of six dispositions identified by differing theorists in the field such as Ennis $(1985,1993)$ and Paul (1995). Within this framework, critical thinking comprises the dispositions to seek 'truth and understanding', to be 'strategic' and to be 'skeptical' (Ritchhart, 2002, p. 27). Similarly, Costa's (2001b) Habits of Mind [HoM] delineate key traits that can be viewed to comprise what I refer to as the dispositional, attitudinal or 'characterological' (Ritchhart, 2002, p. 19) dimension of critical thinking. The HoM draw attention to the habits that are key to intelligent behaviour and thinking. Furthermore, Lipman $(1985,2003)$ coined the notion 'a community of inquiry' (p. 100) that views thinking as a social, collective and collaborative practice. This focus on dispositions is reflected in the Australian Curriculum as it seen as one of the approaches to understanding critical thinking (ACARA, 2015).

However, it must be acknowledged that some theorists draw a distinction between critical and creative thinking and their respective dispositions. In contrast to Ennis (1987) and Facione and Facione (2000), Ritchhart $(2001,2002)$ in his concept of intellectual character, for instance, describes being 'open-minded' and 'curious' as creative thinking dispositions. He also breaks down Paul's (1995) critical thinking dispositions, or 'intellectual traits', into creative thinking ('looking out'), reflective thinking ('looking in') and critical thinking ('looking at'). Thus, while further distinctions such as these are made, they nonetheless illustrate the intrinsic and significant conceptual overlaps in which the Australian Curriculum aptly captures.

Apart from conceptions of critical thinking as comprising cognitive skills and processes - what can be described as the cognitive dimension - the attitudinal, dispositional or 'characterological' dimension of critical thinking highlights the importance of thinking dispositions and attitudes that predispose a person to think critically in daily situations. Thus, while having the ability to think critically is essential, having the natural inclination to do so in various situations is also key (Ennis, 1993; Facione \& Facione, 2000; Ritchhart, 2002; Paul, 1995; Tishman, Jay \& Perkins, 1995).

In offering another definition, Facione (1984) views critical thinking as 'the development and evaluation of arguments' (p. 259). Lipman (2003) contends that it is 'thinking that facilitates good judgment because it relies upon criteria; is self-correcting; and is sensitive to context' ( $p$. 213). Siegel (1991) points out that the critical thinker must also have 'a critical spirit' (p. 18), which can be viewed as the propensity and inclination to think critically that refers to the characterological dimension of critical thinking as discussed.

Splitter (1991) furthered this conception of critical thinking by contending that for critical thinking to occur, there needs to be 'a community of inquiry' (p. 100) - a concept first coined by Lipman $(1985,2003)$ that views thinking as a social, collective and collaborative practice. Similarly, Paul (1995) perceived such thinking as 'dialectical and dialogical' in which critical thinkers must move beyond the atomistic analysis to comprehend the issue at hand and the 'world view' of their 'opponents' (Costa, 2003), or others.

However, Paul (1995) resists pigeon-holing critical thinking and conceptualises it in a number of different ways that should not be viewed as mutually exclusive. His definitions include: 'thinking 
Ab Kadir, M. A. B. (in press) Critical thinking and learner diversity in the Australian Curriculum: implications and epistemological tensions? In: International Journal of the Pedagogies of Learning.

about your thinking while you're thinking to make your thinking better' (p. 91), which has a metacognitive dimension; and the following definition which seems to be characterised by the characterological dimension of thinking:

a unique kind of purposeful thinking in which the thinker systematically and habitually imposes criteria and intellectual standards upon the thinking, taking charge of the construction of thinking, guiding the construction of the thinking according to the standards, assessing the effectiveness of the thinking according to the purpose, the criteria, and the standards (p. 21).

For Paul, (1995) critical thinking as a cognitive process alone is insufficient. Both the propensity to think critically and the attachment of standards he refers to as 'intellectual standards' — the criteria by which to assess the quality of thinking — are also essential. These criteria include clarity, precision, relevance and logical coherence in the act of thinking critically. Paul also underlines their importance by warning against superficiality and the impropriety of certain manifestations of critical thinking, labelling them as 'pseudo critical thinking' (p. 47).

In light of the variety of understandings of critical thinking found in the literature, it is significant that the Australian Curriculum embraces an expansive and multidimensional notion of critical thinking that captures such complexities and richness (Ab Kadir, 2010) when it makes clear that 'each of these approaches (namely the skills, dispositional and community perspectives of critical thinking) has informed the development of the critical and creative thinking capability' (ACARA, 2015). Following this, it can be suggested that critical thinking in the curriculum is to be conceptualized as not only a set of cognitive skills but, importantly, as the development of dispositions or habits of mind that could be demonstrated as a collaborative and social practice in the shape of communities of inquiry. It is evident that in such a multidimensional conception of critical thinking as one of the general capabilities in the Australian Curriculum, the essential skills, capacities and dispositions that are collectively key in the $21^{\text {st }}$ century are embedded. Such expansive conceptualisations of critical thinking will be key if teachers are to teach critical thinking as more than just a grab bag of discrete cognitive skills as teaching critical thinking ought to also include developing the dispositional aspect of it; it is not only about developing critical thinking but also the development of critical thinkers. This is especially important when research has found that teachers' approach to teaching critical thinking is influenced by their conceptualisations of it (Gruberman, 2005; Ab Kadir, 2010). As such, the richer their understandings of critical thinking the richer their approach to teaching it.

\section{Approaches to teaching critical thinking in the Australian Curriculum}

Given that there are a variety of approaches that inform the understandings of critical thinking in the Australian Curriculum, what would it mean for how teachers should go about developing this capability? This would not necessarily be a straightforward answer as, unsurprisingly, research suggests that disagreement exists when it comes to the issue of the most effective approach in teaching critical thinking. In part, this is due to the theoretical differences in the manner in which critical thinking is understood in literature - either as a generalizable skill(s) that can be applicable across diverse domains or as a domain specific activity in which thinking is focused on a particular subject or content. 
Ab Kadir, M. A. B. (in press) Critical thinking and learner diversity in the Australian Curriculum: implications and epistemological tensions? In: International Journal of the Pedagogies of Learning.

Costa (2001a) and Brandt (2001), for instance, divide the approach to teaching thinking into three main categories. These are: teaching of thinking; teaching for thinking; and teaching about thinking (emphasis added). Brandt (2001) describes the teaching of thinking as primarily the teaching of explicit thinking skills 'using teaching methods and special materials not usually found in the typical school curriculum' (p. xii-xiii). Similarly, Costa (2001a) suggests that this also requires that 'teachers instruct students directly in the processes of thinking' (p. 355). However, his conception of this category includes the teaching of thinking dispositions that are also taught directly together with the cognitive skills and operations. This view of thinking instruction is consistent with others like Tishman et al. (1995) and Ritchhart (2002).

Teaching for thinking according to Costa (2001a) 'simply means that teachers and administrators examine, monitor, and strive to create school and classroom conditions that are conducive to children's thinking' (p. 354). This, for instance, includes classroom activities that 'challenge and engage students' minds' and the creation of a larger school climate that models, encourages and supports thinking. The notion of the conducive classroom climate for thinking here is equivalent to Ritchhart's (2002) and Beyer's (1997) notion of 'thoughtful classrooms'.

Brandt (2001) describes teaching about thinking as essentially developing students' metacognition — or to be able to 'think about their own thinking — to become conscious of their own thought processes and improve their ability to control them to some degree' (p. xiii). However, Costa (2001a) broadens this category by further subdividing it into four components. These are: brain functioning; metacognition; great thinkers and epistemic cognition (Costa, 2001a, p. 355). Firstly, brain functioning, primarily refers to the raising of fundamental questions about the cognitive aspect such as 'How do we think?' and 'How do we learn?'. Secondly, metacognition, which denotes '[b]eing conscious of our own thinking and problem-solving during the acts of thinking and problem-solving' (p. 356), can be manifested in classroom activities such as having student discussions about their thinking and learning how to learn. Thirdly, great thinkers, like the name suggests, is essentially about exposing students to figures who are famed for their seminal intellectual achievements such as Albert Einstein and Leonardo Da Vinci. Related to this is the final component, epistemic cognition. This component focuses on the deeper examination of the 'methods' of great thinkers by learning their various processes of 'inquiry, and creativity that underlie their productivity' (Costa, 2001a, p. 356).

Although Costa (2001a) suggests that such kinds of thinking instruction should be constituted in a thinking programme, these thinking approaches also typify the divisions in thinking instruction that pervade the literature. That is, whether thinking is best taught as a set(s) of explicit and generic thinking skills — the 'generalist view' — or as an implicit and integrated component of subject matter teaching — the 'specifist view' (Davies, 2006). The three kinds of thinking instruction approaches can be subsumed under two broad approaches - the skills/generalist approach and the infusion approach. And it is in these tensions that the richness of the manner of ways, in which teachers in the Australian Curriculum can develop critical thinking, lies.

\section{Critical thinking epistemologies and learner diversity in the Australian Curriculum}

While critical thinking has been undergoing an educational resurgence in recent decades, historically, the basic notion of critical thinking can be traced back 2400 years to the time of Socrates, Plato and Aristotle (Paul, 1995). The works of Thomas Aquinas in the Middle Ages 
Ab Kadir, M. A. B. (in press) Critical thinking and learner diversity in the Australian Curriculum: implications and epistemological tensions? In: International Journal of the Pedagogies of Learning.

continued this tradition and development in the area of critical thought and then later by philosophers such as Descartes, Machiavelli, John Locke, Francis Bacon and Thomas Moore. In the $20^{\text {th }}$ century, the likes of John Dewey and Nietzsche became influential. Given this historical overview, it could be said that the works that shaped and furthered the ideas of critical thinking and critical thought, more generally, originated from and are influenced by Western perspectives and value systems over the different eras. These ideas have arguably shaped much of the critical conversations and development in critical thinking and thought that occurred across much of the world over the ages.

It is therefore unsurprising that in contemporary educational reforms related to critical thinking, the notions and understandings of critical thinking are those that have originated from a predominantly Western perspective. As uncovered in the previous sections, the influential education scholars in these areas include Richard Paul, Robert Marzano, Bloom and associates, and Matthew Lipman, to name a few; it is evident that their ideas emanate from very Western traditions and have gone on to influence much of the thinking behind numerous educational reforms related to critical thinking across the world. A case in point is Singapore's landmark educational policy on critical thinking encapsulated in its educational vision, 'Thinking Schools, Learning Nation' (TSLN). On the one hand, Singapore is very much an Asian country noted for its top performing educational system and economic prowess and its educational precepts are largely based on Confucius ethos and values (Ab Kadir, 2010, 2016). But on the other hand, its conceptions of critical thinking in the TSLN policy cannot be described in a similar manner. Policy documents related to its critical thinking initiative indicate that much of the thinking and understandings behind it are influenced by works of Western scholars such Robert Marzano's frameworks which include Dimensions of Thinking and Dimensions of Learning (Ab Kadir, 2010). While the non-Western perspectives of critical thought and thinking such as those originating from Eastern and Oriental traditions, for example Confucius, are only coming to the fore in more recent decades in educational conversations, it is undeniable that much works from the Western perspectives have largely shaped many educational reforms.

Similarly, it could be said that the AC and its conceptions of critical thinking have, unsurprisingly, been shaped by these Western perspectives and traditions and to some extent by its Christian heritage and values. As noted in the previous sections, works such Ron Ritchhart's and other Western scholars have clearly been the sources in which the conceptions of critical thinking in the AC have been shaped. In itself, these Western conceptions of critical thinking and its practices are not necessarily problematic given the known popularity and efficacy of such approaches to developing student critical thinking. However, when set against the Australian context of learners diversity that include the notions of diverse cultures and epistemologies, tensions might manifest.

\section{Learner diversity and learner epistemologies}

Learner diversity is evidently accorded great importance in the AC. The Melbourne Declaration on Educational Goals for Young Australians (MCEETYA, 2008) which shaped the policy context for the Australian Curriculum includes two goals in terms of learner diversity. These are: 'Australian schooling promotes equity and excellence' and 'All young Australians become successful learners, confident and creative individuals' and active and informed citizens (MCEEYTA, 2008). 
Ab Kadir, M. A. B. (in press) Critical thinking and learner diversity in the Australian Curriculum: implications and epistemological tensions? In: International Journal of the Pedagogies of Learning.

Furthermore, the AC stipulates that:

All students are entitled to rigorous, relevant and engaging learning programs drawn from a challenging curriculum that addresses their individual learning needs. The Australian Curriculum recognises that the needs of all students encompass cognitive, affective, physical, social, and aesthetic curriculum experiences (ACARA, 2013, p. 20).

The aspects of diversity include disability, gifted and talented and EAL students (ACARA, 2013). What is not clear, however, in these documents is the notion of the diversity in learner epistemologies and how these might be accounted for.

The notion of learner epistemology can be linked to the notion of personal epistemologies. Literature on the constructivist perspectives of learning recognise the primary role for every person in making meaning from experience and then building knowledge from that experience. That is, people make sense of what they experience by linking it to their prior knowledge or, if the experience is new for them, augmenting what they know to process novel experiences. Taking this into consideration, personal epistemologies can be seen as the manner of how people's ways of knowing and action that stem from their capacities, prior experiences and encounters with the social world encompassing their life histories (Billet, 2009). This is also inevitably shaped by individuals' cultural and value systems that shape their perspectives and world views. And in the context of the increasing cultural and ethnic diversity in Australian classrooms it would imply that these epistemologies could be as diverse among learners.

The implementation of Western understandings of and approaches to critical thinking in educational reforms in this area have been known to create tensions in learning and teaching contexts which are not naturally congruent with Western epistemologies. A case in point is Singapore's implementation of its critical thinking objective encompassed in its educational reform, Thinking Schools, Learning Nation (TSLN). Research suggests that one of the reasons for the inefficacy of the implementation of critical thinking in TSLN is attributed to Singapore's Eastern cultural value systems (for example, Koh, 2002; Lim, 2014) and by extension the incongruence between learner (and to some extent even teacher) epistemologies, on the one hand, and the Western notions and practices of critical thinking, on the other. A stumbling block on the path of successful implementation of critical thinking is the deeply entrenched culture of obedience and conformity which have been largely shaped by learner and teacher epistemologies that seem to be counter-intuitive to Western notions of and approaches to critical thinking. For example, some teachers' experiences and anecdotes suggest how these tensions seem to manifest in the general reticence and broader lack of criticality in lessons amongst students when critical thinking questions are posed in their classes (Ab Kadir, 2010). Other teachers report the frequently displayed student apathy towards critical thought. What seems to be more noticeable instead was students' predilection towards 'right answers' and examination preparations in lessons. Similar tensions are also seen in other Asian countries such as Hong Kong, Korea and Japan (Fung \& Howe, 2014; McGuire, 2007). As with these countries, Singapore is argued to be moulded on a Confucian value system that compels the rights and privileges of the larger society over the individual in which critical questioning of elders and authority, for example, are eschewed. This value system are also imbued in Singapore's national Shared Values (Tan, 2001) in which the interests of larger community and society supersede the rights and privileges of the individual. 
Ab Kadir, M. A. B. (in press) Critical thinking and learner diversity in the Australian Curriculum: implications and epistemological tensions? In: International Journal of the Pedagogies of Learning.

Such tensions engendered between the clash between Western understandings and concepts, and non-Western epistemologies also seem to manifest itself in Islamic contexts according to some studies. Diallo (2014), for instance, reported on how students in the United Arab Emirates displayed resistance and tensions when confronted with Western literature and ideas. Interviews with the Western educators in the study suggest how these students showed an aversion towards such Western materials and ideas which contradict their own values, beliefs and epistemologies. However, despite such resistance and tensions it must be noted that contrary to widely held beliefs, Islam and critical thinking are compatible and in fact Islam promotes it with the caveat that these practices do not contradict Islamic precepts and beliefs.

\section{Pedagogical implications and tensions: diverse learners, diverse epistemologies}

While it cannot be said that the larger Australian context is similar to the Asian and Islamic contexts previously discussed, what cannot be discounted is how the increasing diversity of learners and their accompanying epistemologies in the Australian classrooms can engender similar tensions. In terms of the national ethnic make-up, the Australian Bureau of Statistics report that $25 \%$ of Australia's 22 million people were born overseas; 46 per cent have at least one parent who was born overseas; and nearly 20 per cent of Australians speak a language other than English at home (Australian Bureau of Statistics, 2013a). On the other hand, overseas migration represented 60 per cent of Australia's population growth in 2013 (Australian Bureau of Statistics, 2014). While people born in the United Kingdom carry on to be the biggest group of overseas-born residents (5.3 per cent), which is followed by New Zealand ( 2.6 per cent), what is interesting is that China (1.8 per cent), India (1.6 per cent) and Vietnam make up the (0.9 per cent) make up the other significant groups (Australian Bureau of Statistics, 2013b). And In 201314, 163017 people from more than 190 countries were granted Australian citizenship (Department of Immigration and Border Protection, 2014).

Given the above statistics, it is evident that such diversity would similarly be reflected in Australian classrooms, if not at this present stage, then gradually over time. Thus, some issues that arise in the context of developing critical thinking citizens in the AC founded upon Western understandings an epistemologies amidst such presumably diverse learner epistemology are: what are the implications and tensions that might be engendered when this student diversity is also reflected in the diversity of learner epistemologies that students bring with them into the classroom? How can teachers mediate these epistemological tensions that are engendered between student diverse epistemologies, on the one hand and the predominantly Western conceptions and approaches to developing critical thinking in the AC, on the other?

It must be recognised that student diversity does not end with and cannot be simply demarcated along the lines of 'student disability', 'giftedness' and EAL alone. Diversity ought to account for the diversity in learner epistemologies too. Thus, in the course of developing student critical thinking in the $\mathrm{AC}$, the challenge for teachers is to find ways to mediate these tensions and clashes between presumably increasing non Western learner epistemologies and critical thinking approaches and conceptions, which are predominantly Western. The cognitive, as well as epistemological, dissonance in a section of Australian students when confronted with seemingly foreign Western notions and approaches could be problematic. For instance, Australian learners who come from Eastern contexts such as China, India and Vietnam, with traditionally and generally more conservative epistemologies might find that the very premise of critical thinking 
Ab Kadir, M. A. B. (in press) Critical thinking and learner diversity in the Australian Curriculum: implications and epistemological tensions? In: International Journal of the Pedagogies of Learning.

to critique and interrogate previously taken for granted assumptions and beliefs unsettling. This, as previously highlighted, has been found in Eastern contexts such as Singapore, Hong Kong, Korea and Japan in which the Eastern values have created tensions with the Western notion of critical thinking and practices.

One way teachers can mediate these epistemological tensions before they manifest in the classroom is to have a critical appreciation that diversity in the classroom transcends aspects such as disability, giftedness, English competency, ethnicity, and sexuality. The implicit diversity in learner epistemologies must, equally, be recognised. In this regard, Billet (2009) suggests that understandings of learners' personal epistemologies can support how best the curriculum and pedagogy might be conceived and enacted by teachers. For example, before teaching critical thinking in the AC or controversial topics such as evolution theory or gender and sexuality issues, teachers could establish the nature and diversity of their learner epistemologies by getting students to engage with questions that give teachers the insights into their students' world views, beliefs about knowledge, learning and the like. Having insights into such views that learners' possess can help teachers to be better able to position and implement the curriculum that suits this diversity. Furthermore, developing and possessing an acute sense of intercultural understandings and capability would also help teachers manage the learner diversity and negotiate these potential tensions. Furthermore, as Diallo (2014) suggests in the context of cross cultural teaching, such an "educational setting requires Western-trained teachers to adapt ...[students'] positionality, choice of teaching material, textbooks, epistemologies, and, above all their cultural symbolism to the cultural space (epistemologies, cultural and religion values)" (p. 12). Therefore it is these delicate pedagogical calibrations that could help assuage the epistemological clashes and tensions that are engendered between Western curricular approaches to critical thinking practice and non-Western learner epistemologies.

It is argued that the successful development of critical thinkers in schools is predicated on not only teachers' knowledge in the area of critical thinking but also creating the right conditions in schools and classrooms (Ab Kadir, 2016) as well as taking into account learner epistemologies to minimise the epistemological tensions. The right school culture and support towards this agenda is also fundamental if teachers are to be successful in the development of critical thinking in diverse learners. And if teachers are indeed the key stakeholders of education and ultimate agents in the successful implementation of educational initiatives as many have argued (e.g. Fullan, 2001; Hargreaves, 1994; Groundwater-Smith, 2005), then it would be vital that the nature and diversity of learners' epistemologies are accounted for and the conducive learning conditions are created.

\section{Conclusion}

It is clear that the Australian Curriculum focus on critical and creative thinking and its multifaceted understanding of it gives its teachers a rich array of ways of conceptualizing and teaching it. However, the issues as highlighted in this discussion could be found in the epistemological tensions that are engendered between the clash of Western notions of and approaches to critical thinking in the $\mathrm{AC}$, and the increasing non-Western learner epistemologies in Australian classrooms when these are employed in the teaching of the learning areas in the AC. Therefore, the challenge resides with schools and teachers in the Australian Curriculum to be equipped with the knowledge of the implicit learner epistemologies and a level of intercultural literacy before they can successfully develop 'young learners to be creative, innovative, 
Ab Kadir, M. A. B. (in press) Critical thinking and learner diversity in the Australian Curriculum: implications and epistemological tensions? In: International Journal of the Pedagogies of Learning.

enterprising and adaptable, with the motivation, confidence and skills to use critical and creative thinking purposefully' (ACARA, 2015). The questions of how teachers have been prepared or are being prepared in this area do not seem to have been explicitly addressed in discourses in the area and therefore might warrant further inquiry and interrogation.

Furthermore, it might be instructive that in the discourses and conceptions of student diversity, the notion of diversity in learner epistemologies also becomes part of the conversation. Given its rather implicit and hidden nature, an appreciation of learner epistemologies in the formulation and enactment of curriculum objectives is essential. Doing so might help teachers to mitigate tensions that manifest on the path of the development of critical thinkers and thus allow them to do so in a more effective manner.

Given the potential issues discussed here, there is certainly no shirking away from them as the realisation of developing critical thinkers is a vital aim in the increasing diversity of school leavers in Australia as envisioned. This is especially so when teachers are considered to be at the heart of educational change and that the efficacy of any educational change boils down ultimately to 'what teachers do and think' (Fullan, 1994, 2001). And going forward, this is certainly one area that further research can be directed towards to get a sense of what it is actually that 'teachers do and think' in regard to the development of a key capability in the Australian Curriculum - critical thinking - in the increasing diversity of the Australian classroom which seems more multifaceted than imagined.

\section{References}

Ab Kadir, M. A. (2016). Engendering a culture of thinking in a culture of performativity: the challenge of mediating tensions in the Singaporean educational system. Cambridge Journal of Education, (In press), 1-20. DOI: 10.1080/0305764X.2016.1148115

Ab Kadir, M. A. (2010). Rethinking 'Thinking Schools, Learning Nation': teachers' and students' perspectives of critical thinking in Singaporean education (Unpublished doctoral dissertation). Melbourne: University of Melbourne.

Anderson, L. W., Krathwohl, D. R., Airasian, P. W., Cruikshank, K. A., Mayer, R. E., Pintrich, P. R., et al. (2001). A taxonomy for learning, teaching and assessing: a revision of Bloom's taxonomy of educational objectives. USA: Addison Wesley Longman, Inc.

Australian Bureau of Statistics,3101.0-Australian Demographic Statistics, September 2013 (2014).

Australian Bureau of Statistics, 4102.0-Australian Social Trends (2013a).

Australian Bureau of Statistics, 3412.0-Migration, Australia, 2011-12 and 2012-13 (2013b).

Australian Curriculum, Assessment and Reporting Authority (ACARA). (2015.). Retrieved June 5, 2015, from http://www.australiancurriculum.edu.au/GeneralCapabilities/Pdf/Criticaland-creative-thinking. 
Ab Kadir, M. A. B. (in press) Critical thinking and learner diversity in the Australian Curriculum: implications and epistemological tensions? In: International Journal of the Pedagogies of Learning.

Australian Curriculum, Assessment and Reporting Authority (ACARA) (2013) Student Diversity and the Australian Curriculum Advice for principals, schools and teachers. Retrieved from http://www.australiancurriculum.edu.au/studentdiversity/pdf/studentdiversity

Bailin, S., Case, R., Coombs, J. R., \& Daniels, L. B. (1999a). Common misconceptions of critical thinking. Journal of Curriculum Studies (31), 269-283.

Berliner, D. (2009). Rational responses to high-stakes testing and the special case of narrowing the curriculum. Keynote address presented at the $3^{\text {rd }}$ Redesigning Pedagogy International Conference, Singapore.

Beyer, B. K. (1997). Improving student thinking: a comprehensive approach. Boston: Allyn and Bacon.

Billett, S. (2009). Conceptualizing learning experiences: Contributions and mediations of the social, personal and brute, Mind, Culture and Activity, 16 (1) 32-47

Bloom, B. S. (1956). Taxonomy of educational objectives, Part 1, Cognitive domain. New York: Longmans Green

Brandt, R. S. (2001). Foreword. In A. Costa (Ed.), Developing minds: a resource book for the teaching of thinking (3rd ed., pp. xii-xiv). Victoria, Australia: Hawker Brownlow Education.

Costa, A. (2001a). Teaching for, of, and about thinking. In A. Costa (Ed.), Developing minds: a resource book for teaching thinking (3rd ed., pp. 354-358). Victoria, Australia: Hawker Brownlow Education.

Costa, A. (2001b). What are habits of mind? Retrieved June 1, 2008, from http://www.habits-ofmind.net/whatare.htm

Costa, A. (2003). Communities for developing minds. In D.Fasko (Ed.), Critical thinking and reasoning: current research, theory, and practice. New Jersey: Hampton Press, Inc.

Davies, W. M. (2006). An 'infusion' approach to critical thinking: Moore on the critical thinking debate. Higher Education Research and Development 25(2), 179-193.

deBruin, W., Parker, A.., Fischhoff, B. (2007). Individual differences in adult decision-making competence'. Journal of Personality and Social Psychology, Vol 92(5). 938-956.

Department of Immigration and Border Protection: Facts and Statistics - Australian citizenship statistics (2014).

Diallo, I. (2014). Emirati students encounter Western teachers: tensions and identity resistance. Learning and Teaching in Higher Education: Gulf Perspectives, 11(2). http://lthe.zu.ac.ae

Fung, D. \& Howe, C. (2014). Group work and the learning of critical thinking in the Hong Kong 
Ab Kadir, M. A. B. (in press) Critical thinking and learner diversity in the Australian Curriculum: implications and epistemological tensions? In: International Journal of the Pedagogies of Learning.

secondary liberal studies curriculum. Cambridge Journal of Education, 44, 245-270.

Ennis, R. H. (1993). Critical thinking assessment Theory into Practice, 32(3), 179-186.

Ennis, R. H. (1987). A taxonomy of critical thinking dispositions and abilities. In J. B. Baron \& R. J. Sternberg (Eds.), Teaching thinking skills: theory and practice (pp. 9-26). New York: Freeman.

Ennis, R. H. (1985). A logical basis for measuring critical thinking skills. Educational Leadership (43), 44-48.

Facione, P. A. (1984). Toward a theory of critical thinking. Liberal Education, 70, 253-261.

Facione, P. A., Facione, N. C., \& Giancarlo, C. A. (2000). The disposition toward critical thinking: its character, measurement, and relationship to critical thinking. Informal Logic_(20), 6184.

Fullan, M. (1994). Change forces: probing the depths of educational reform. London: The Falmer Press.

Fullan, M. (2001). The new meaning of educational change ( $3^{\text {rd }}$ ed.). New York: Teachers College Press.

Gardner, H. (2008). Five minds for the future. Boston, MA: Harvard Business School Press

Goh, C. T. (1997). Shaping our future: thinking schools, learning nation, speech by Prime Minister Goh Chok Tong at the opening of the $7^{\text {th }}$ International Conference on Thinking. Retrieved February 28, 2007, from http://www.moe.gov.sg/speeches/1997/020697.htm

Gruberman, R. (2005). Teacher conceptualizations of higher-order thinking: a case study. Boston College, Lynch Graduate School of Education, Boston.

Groundwater-Smith, S. (2005). The everyday neglect of student voice in our schools. Paper presented at the Contemporary Questions in Curriculum Seminar Series.

Hargreaves, A. (1994). Changing teachers, changing times: teachers' work and culture in the postmodern age. London: Cassell.

Hunt, E. (1995). Will we be smart enough? a cognitive analysis of the coming workforce. New York: Russell Sage Foundation.

Koh, A. (2002). Towards a critical pedagogy: creating 'Thinking Schools' in Singapore. Journal of Curriculum Studies, 34(3), 255-264.

Krathwohl, D. R. (2002). A revision of Bloom's taxonomy: an overview. Theory Into Practice 41(4), 212-218. 
Ab Kadir, M. A. B. (in press) Critical thinking and learner diversity in the Australian Curriculum: implications and epistemological tensions? In: International Journal of the Pedagogies of Learning.

Lim, L. (2014). Critical thinking and the anti-liberal state: The politics of pedagogic recontextualization in Singapore. Discourse: Studies in the Cultural Politics of Education, 35, 692-704.

Lipman, M. (2003). Thinking in education. Cambridge: Cambridge University Press.

Lipman, M. (1985). Thinking skills fostered by philosophy for children. In J. W. Segal, S. F. Chipman \& R. Glaser (Eds.), Thinking and learning skills (Vol. 1). Hillsdale, NJ: L. Erlbaum.

McGuire, J. (2007). Why has the critical thinking movement not come to Korea? Asia Pacific Education Review, 8, 224-232.

Ministerial Council on Education, Employment, Training and Youth Affairs [MCEETYA]. (2008), Melbourne Declaration on Educational Goals for Young Australians. Carlton South, VIC: Author.

Nagappan, R. (1998). Teaching higher order thinking skills in language classrooms: the need for transformation of teaching practice. Unpublished $\mathrm{PhD}$, Michigan State University Michigan.

Paul, R. (1995). Critical thinking: how to prepare students for a rapidly changing world. California: Foundation for Critical Thinking.

Ritchhart, R. (2001). From IQ to IC: a dispositional view of intelligence. Roeper Review, 23(3), 143-150.

Ritchhart, R. (2002). Intellectual character: what it is, why it matters and how to get it. San Francisco: Jossey Bass.

Scheffler, I. (1989). Reason and teaching. Indianapolis: Hackett.

Siegel, H. (1991). The generalizability of critical thinking. Educational Philosophy and Theory, $23(1), 18-30$.

Sigel, I. E. (1984). A constructivist perspective for teaching thinking. Educational Leadership, $42(3), 18-21$.

Splitter, L. J. (1991). Critical thinking: what, why, when and how. Educational Philosophy and Theory, 23 (1), 89-109.

Tan, E. (2001). Singapore Shared values. Retrieved 12 May 2008, from http://infopedia.nl.sg/articles/SIP_542_2004-12-18.html

Tishman, S., Perkins, D. N., \& Jay, E. (1995). The thinking classroom: learning and teaching in a culture of thinking. Needham Heights, MA: Allyn and Bacon. 